\title{
ATMOSPHERIC TRANSPORT IN COMPLEX TERRAIN AT LOS ALAMOS, AREA G
}

$$
24-4 k-460
$$

Author(s):

Erik L. Vold

\section{U.S. Department of Energy,}

as support documentation for the

Los Alamos Area G Performance Assessment
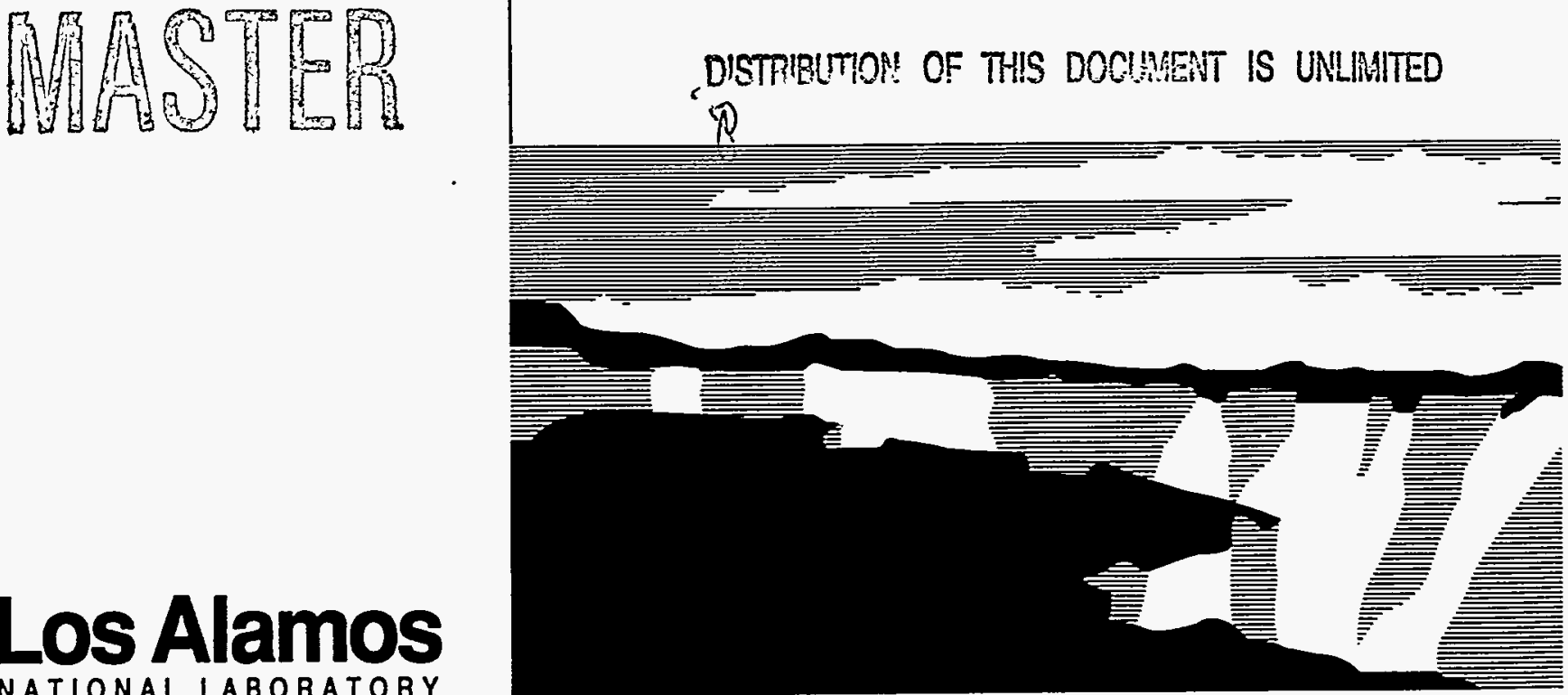

Los Alamos National Laboratory, an affirmative action/equal opportunity employer, is operated by the University of Califomia for the U.S. Department of Energy under contract W-7405-ENG-36. By acceptance of this article, the publisher recognizes that the U.S. Govemment retains a nonexclusive, royalty-free license to publish or reproduce the published form of this contribution, or to allow others to do so, for U.S. Government purposes. Los Alamos National Laboratory requests that the publisher identify this article as work performed under the auspices of the U.S. Department of Energy. The Los Alamos National Laboratory strongly supports academic freedom and a researcher's right to publish; as an institution, however, the Laboratory does not endorse the vieupoint of a publication or guarantee its technical correctness. 


\section{DISCLAIMER}

This report was prepared as an account of work sponsored by an agency of the United States Government. Neither the United States Government nor any agency thereof, nor any of their employees, make any warranty, express or implied, or assumes any legal liability or responsibility for the accuracy, completeness, or usefulness of any information, apparatus, product, or process disclosed, or represents that its use would not infringe privately owned rights. Reference herein to any specific commercial product, process, or service by trade name, trademark, manufacturer, or otherwise does not necessarily constitute or imply its endorsement, recommendation, or favoring by the United States Government or any agency thereof. The views and opinions of authors expressed herein do not necessarily state or reflect those of the United States Government or any agency thereof. 
LANL Area G Performance Assessment Appendix:

\title{
ATMOSPHERIC TRANSPORT IN COMPLEX TERRAIN AT LOS ALAMOS, AREA G
}

Erik L. Vold

\begin{abstract}
This report documents the atmospheric dispersion used in the Area G Performance Assessment for off-site airborne dose calculations. Potential airborne contaminants from the mesa top disposal facility disperse in the complex terrain dominated by narrow mesas in parallel to narrow canyons. The dispersion is characterized by site-specific values of $\chi / Q\left[\left(\mathrm{Ci} / \mathrm{m}^{3}\right) /(\mathrm{Ci} / \mathrm{s})\right]$ at each of two designated receptor locations, a 'maximum off-site dose' location and a nearby population center (White Rock, NM). The values of $\chi / Q$ in each of the sixteen wind sectors are first estimated with the CAP-88 computer code using 1992 annual meteorologic data from Area G and assuming an area source for release. This data captures the dominant wind direction on the mesa tops from the SSW. These dispersion parameters are assumed to apply to open, flat terrain and must be corrected for the complex mesa and canyon terrain surrounding the Area $G$ site. Additional meteorologic data has been collected over two years from six remote temporary meteorological stations operated on the mesas and in the canyons immediately around Area G. These data indicate that the wind flow in the canyons is exclusively bimodel, flowing up canyon during the day and down canyon at night. It is conservatively assumed that all ground level releases from Area $G$ which blow out across an adjacent canyon become entrained in the canyon flow. This effectively combines the contaminant release for several sectors into a single canyon flow which is upstream during the day or downstream at night. This canyon channeling mechanism is implemented in the model by summing the wind sector dispersion factors over those sectors appropriate to the geometry for a release from Area $G$ toward either adjacent canyon. The result is that the location of the 'maximum off-site' individual is found to be up canyon to the north (in Canada del Buey, limited by daytime flow) where the maximum dispersion parameter is $(\chi / Q)_{\max }=$ $5.5 \times 10^{-5} \mathrm{~s} / \mathrm{m}^{3}$. The maximum dispersion parameter at a population center, $(\chi / Q)_{\text {pop, }}$ is in White Rock to the ESE (limited by nighttime down canyon flow), where $(\chi / Q)_{p o p}=1.3 \times 10^{-5} \mathrm{~s} / \mathrm{m}^{3}$. At both locations the analysis indicates the canyon channeling effect increases $\chi / Q$ by about a factor of 2.4 over that expected in any single downwind sector. Uncertainties are examined in some detail.
\end{abstract}




\section{ATMOSPHERIC TRANSPORT IN COMPLEX TERRAIN AT LOS ALAMOS, AREA G}

\section{Introduction}

Atmospheric transport is evaluated from a source at the Los Alamos Area $G$ disposal site to an off-site receptor at a location of maximum contaminant concentration and to a receptor at a population center (White Rock). Part of the assessment is to determine the location of maximum airborne concentrations, which is complicated by the site location in complex terrain. The assessment can be written in terms of the factors including source strength, $S$, source release rate, $R$, atmospheric dispersion, $\chi / Q$, and dose conversion, $D_{f}$, related as

$$
D[m r e m / y r]=S[C i / m 3] R\left(\frac{C i / s}{C i / m 3}\right) \chi / Q[s / m 3] D_{f}\left(\frac{m r e m / y r}{C i / m 3}\right) .
$$

The airborne transport is characterized with a dispersion value, $\chi / Q$, equal to the receptor location concentration, $\chi[\mathrm{Ci} / \mathrm{m} 3]$, per continuous source term release, $Q[\mathrm{Ci} / \mathrm{s}]$, assumed to be valid for a quasi-steady state release. This report details the site-specific specification of the $\chi / Q$ values for the critical receptor locations near Area $G$ used in the site Performance Assessment.

The main report on the site Performance Assessment describes the airborne source nuclide strength, $S$, which has been sorted from the disposal inventory. A separate report [Vold,96] describes detailed numerical calculations to determine the time dependent release rate, $R[t]$, for three nuclide sources. These were chosen to bound the range of releases and to compare to airborne releases calculated in the simpler steady state analytic solutions implemented within the PA as a cross check on accuracy of the solutions. The output, from the atmospheric transport and dispersion model combined with the source and source release terms, is the airborne concentration at the critical receptor location which becomes input to the dose assessment model for immersion, inhalation, and deposition pathways.

Estimation of atmospheric dispersion of pollutants has an established history using a Gaussian plume solution with the plume spreading related to 
the Pasquill-Gifford classification system of atmospheric stability [Slade,68]. This method of determining atmospheric pollutant concentration has been implemented in computer codes [CAP-88] as required for assessments by the U.S.EPA [ EPA - 40CFR61]. The method and the stability classification system was developed for dispersion in relatively flat open terrain. The focus of the present study is to document the CAP- 88 results at Area G and the correction factors that are used to apply the results to the complex terrain, a network of mesas and canyons.

An important issue for the complex terrain dispersion correction factor is what fraction of the airborne material which is released from a ground level source on the mesa top, blows out over an adjacent canyon and becomes entrained in the canyon wind flow. Recent simulations [Costigan,et.al.96] suggest this fraction is significantly less than one, but these simulations do not completely and accurately reproduce the distinct mesa top and canyon flow fields. A tracer study conducted in the local area suggests only limited 'channeling' by the canyon wind flows [Archuleta,et.al.,78], and thus the canyon entrainment fraction would be less than one. To be conservative, this study assumes a fraction equal to one, and this is incorporated as a correction factor to the Gaussian plume dispersion factor as detailed in this study.

\section{Data Review}

An aerial view in Fig.1 of northern New Mexico from the NNE sector shows the NNE - SSW orientation of the Rio Grande valley between the Jemez mountains to the west and the Sangre de Cristo mountains to the east. This channels the dominant daytime winds observed at Los Alamos from the south or southwest as seen in the day time windrose in Fig.4. A computer generated surface of the Los Alamos terrain near Area G is seen in Fig.2 (with enhanced vertical scale) which shows the complex finger-like mesas predominantly spanning from the west or NW to the east or SE. The disposal facilities are on top of the narrow finger mesa, Mesita del Buey. The small scale canyons include Canada del Buey to the north of Area G and Pajarito Canyon to the south, which both channel a nighttime drainage wind. The mesa top nighttime windrose (Fig.5) shows that the mesa top flow is generally consistent with the canyon drainage although there is a large variation in the mesa top nighttime wind direction. The annual wind rose (for day and night 
time observations combined) is shown in Fig. 3 for comparison and for use in this analysis. Meteorologic data is summarized annually in the Los Alamos Environmental Surveillance Reports (e.g., see ref.ESR'94) and was described in some detail previously [Bowen,90].

The computer generated view of the topography surrounding Area $G$ (Fig.3) shows six remote meteorological towers which have been collecting 15 minute averaged field data since early 1994. As part of an assessment to understand the flow field and thus dispersion in the local complex terrain, these six portable meteorological towers (of a type originally designed for monitoring at the Nevada Test Site) were sited, two at mesa top locations, one just east of the site where the mesas have dissipated to mild ridges, and three in the canyons adjacent to the disposal site mesa. Since then, the towers have collected horizontal wind velocities, pressure, temperature, relative humidity and a radiation gamma reading every fifteen minutes. In an on-going effort, the data base is being analyzed for trends [Vold,et.al.,95] and to provide a basis for comparison to computational modeling efforts to predict the flow fields [Costigan,et.al.,96, and Celada and Vold,96].

The mesa top flow is seen to be similar at different points, while the mesa top and canyon flows are observed to be quite different from each other. The dominant daytime mesa top wind flow is from the $S$ to SW (or often in the opposite direction), directed by the Rio Grande canyon between the Jemez and the Sangre de Cristo mountains. This flow has a large variance in direction. The mean and variance can be approximately inferred from the histogram chart in Fig.6a. This plot shows the frequency distribution of wind over the two variables of wind direction (labeled degree, angle wind is from) and the hour of day, compiling all 15 minute data from the month of June, 1995 (taken to be a 'typical' or characteristic month).

Similar plots of wind frequency distribution for wind direction and time of day are shown in Fig.6b for one of the canyon locations. The local canyon flows are seen to be very 'precisely bi-modal', meaning flow is directly up canyon during the day, down canyon at night, and with an abrupt change, within 1-2 15-min. sample intervals, for either transition. The nighttime mesa top flow slowly rotates to follow the canyon drainage direction on a variable time scale, some nights never really 'catching up' to the canyon drainage flow. More detailed analyses of the canyon verses mesatop meteorological data is available [Vold, et.al. 95]. 
An implication for atmospheric transport is that to the extent an airborne release from a mesa top site (Area G) crosses an adjacent canyon, it can become entrained in the canyon flow field, and thus contaminant contributions from several mesa top wind sector directions potentially add together into a canyon flow. In this case, several wind rose sectors may impact a single downwind canyon receptor location. It is assumed to be conservative for this study, that canyon channeling of airborne contaminant above the canyon becomes entrained within the canyon.

A comparison of the mesa top wind roses, and the results from the canyons, was made with respect to the actual geometry of the canyons. Daytime windrose sectors from the WSW to the ESE sectors transport airborne contaminants toward the Mesita del Buey canyon to the north and some fraction of those contaminants will be entrained in the up-canyon daytime flow, and thus end up at a single downwind location in the bottom of Mesita del Buey canyon, which is up-canyon from Area G. Each canyon adjacent to the Area $G$ mesa top site will then have a significant contaminant concentration enhancement due to this canyon channeling effect. A simple quantification of these effects from the complex terrain is described in the following. Based on the appropriate weighting of the site wind roses, the point of maximum off-site concentrations of a disposal site source is determined to be up Mesita del Buey canyon and to the north of the disposal site mesa.

\section{Complex Terrain Atmospheric Transport Model}

\section{Critical Off-site Location}

The atmospheric transport in complex terrain is assumed to be characterized by a dispersion value, $(\chi / Q)_{C}$, appropriate to a critical canyon location estimated as

$$
\left(\frac{\chi}{Q}\right)_{C}=\left(\frac{u_{m}}{u_{c}}\right) \sum_{\theta} f_{\theta}\left(\frac{\chi}{Q}\right)_{G P-\theta^{\prime}}
$$

where 


$$
\left(\frac{\chi}{Q}\right)_{G P-\theta} \text { is the Gaussian plume dispersion into wind sector, } \theta,
$$

determined for the appropriate source geometry and mesa-top meteorology data, and evaluated at the receptor location distance,

$\left(\frac{u_{m}}{u_{c}}\right)$ is the ratio of annual averaged wind speed observed on the mesa top, $m$, to that in the canyon, $c$,

$\sum_{\theta} f_{\theta}$ is a sum over wind sectors, $\theta$, of the fraction, $f_{\theta}$, of the mesa top release which becomes entrained in the canyon flow, and thus is channeled by the canyon towards the receptor location, $c$.

The summation accounts for the increase in concentration by canyon channeling over long term releases, that is, dispersion from several mesa top wind sectors add together in the canyon stream flow. The above expression does not include effects of a 'rotor' wind pattern which may result in deeper canyons and could further increase the canyon site concentrations by increasing the canyon residence time for an air parcel.

An important issue is the number of sectors which the summation should include. In an examination of the wind rose from the mesa top location with the area map, the range of sectors likely to contribute to flow into either adjacent canyon during the day or the night were determined. The greatest frequency in the wind rose data clearly involves those sectors blowing towards Canada del Buey to the north (dominated by the daytime flow) and the geometry shows sectors from the WSW to the ESE are likely contributors.

For a ground level release it is conservatively assumed that $f_{\theta}=1$, that all the release becomes caught in the 'downwash' leeward of the mesa and then moves with the canyon flow. During the day this will be up canyon and during the night this will be down canyon. At Area G, flow towards Canada del Buey is more frequent in the daytime than in the night so the critical receptor will be upstream in Canada del Buey due primarily to daytime conditions in the canyon. The available data for dispersion, $\chi / Q$, is based on the annual averaged data (for day and night time conditions combined) so then the canyon dispersion must be corrected for the daytime frequency in the specified sector range relative to that for the total day and night time data. 
This allows us to rewrite the above equation for practical evaluation at Area $G$ as

$$
\left(\frac{\chi}{Q}\right)_{c}=\left(\frac{u_{m}}{u_{c}}\right) \frac{c d f_{d a y}}{c d f_{a n}} \sum_{\theta=E S E}^{\theta=-N \overline{L S} W}\left(\frac{\chi}{Q}\right)_{G P}
$$

where $\left(\frac{\chi}{Q}\right)_{G P}$ is the Gaussian plume dispersion for a given wind sector, $\theta$, evaluated from the annual averaged data base, and $c d f_{d a y}$ is the wind cumulative distribution frequency over the sectors of concern evaluated for daytime hours only, and $c d f_{a n}$ is the annual cumulative frequency distribution evaluated over the $24 \mathrm{hr}$ data base. Thus,

$$
c d f_{d a y}=\sum_{\theta=E S E}^{\theta=W S W} d f_{d a y}, \quad \text { and } \quad c d f_{a n}=\sum_{\theta=E S E}^{\theta=W S W} d f_{a n}
$$

where $d f$ is the distribution frequency or (wind rose sector percentage/100) for the daytime hours (day) or for all hours (an). Examination of the data for the annual, daytime and nighttime Area $G$ wind roses (Fig.3-5) shows that $c d f_{a n}(\theta=E S E, W S W)=0.39$ and $c d f_{d a y}(\theta=E S E, W S W)=0.53(0.5)$, since $53 \%$ of the daytime occurances are from this range of wind sectors. It is assumed that half of the total occurances are recorded on the 'daytime' windrose, and that the actual bimodal behaviour observed in the canyons is split in time similarly to the split which defines 'daytime' or nighttime' conditions in establishing the windrose data. This gives $\left(c d f_{d a y} / c d f_{a n}\right)=0.68$ or $68 \%$ of the southerly winds which impact the Canada del Buey upstream critical receptor occur during the day. This simplification ignores the different distributions of stability class which exist in the daytime compared to all hours.

Data from the three canyon locations at Area $G$ and a fourth nearby canyon (TA41 in Los Alamos Canyon) were pooled to get a canyon average speed, $u_{C}$, found to be $1.55 \mathrm{~m} / \mathrm{s}$. Data from the four meteorological towers identified as located on 'mesa-top sites' (including two near White Rock where the mesas have dissipated to mild ridges) in the immediate vicinity of Area $G$ were pooled to get the mesa-top average wind speed of $2.63 \mathrm{~m} / \mathrm{s}$. The ratio of speeds needed in the above equation is 1.7 . 
An atmospheric transport assessment for Area $G$ was recently completed [Kowalewsky,et.al., 1995] in which the Gaussian plume dispersion from an area source at Area $G$ was determined using a version of CAP-88 [ref: $C A P-88]$. The results include a table of $(\chi / Q)$ values by sector (wind towards) and by downwind distance, shown in Table I. The source area used in the calculation was 60 acres corresponding to the whole Area $G$ site. For a dispersed area source this large, the code does not compute receptor locations any closer than $500 \mathrm{~m}$. Considering the dimensions of Area $G$ and that of the mesa and adjacent canyons (see Fig.2 for example, noting that Area $G$ as indicated in that figure is almost $2 \mathrm{~km}$ long) it is reasonable to take $500 \mathrm{~m}$ as a minimum distance to a critical receptor location. The actual geometry is simplified by assuming this down wind distance applies to each of the wind sectors contributing to the canyon flow.

Summing the ESE to WSW values of $(\chi / Q)$ for the $500 \mathrm{~m}$, location in the table, multiplying by the wind speed ratio of 1.7 , and the daytime occurance frequency of 0.68 gives the final dispersion value for the critical canyon receptor location corrected for the complex terrain, of $\left(\frac{\chi}{Q}\right)_{c}=5.5 \times 10^{-5}$ $s / m 3$.

It is interesting to note that the Gaussian plume maximum dispersion in any single wind sector over this range is $1.35 \times 10^{-5} \mathrm{~m} 3 / \mathrm{s}$ (to the ENE). With the 1.7 wind speed correction, this means that a canyon channeling factor,

$$
\sum_{\theta} f_{\theta}\left(\frac{\chi}{Q}\right)_{G P} /(\chi / Q)_{\text {sector-max }} /\left(u_{m} / u_{c}\right)=5.5 \times 10^{-5} / 1.35 \times 10^{-5} / 1.7=2.4,
$$

or the canyons can channel contaminants from Area $G$ to concentrate long term averages to about two and one half times that expected from a Gaussian plume prediction. This concentration only applies to long term chronic releases, so that the annual average wind rose applies.

Dispersion values, $\chi / Q$, in a single sector at distances closer than the $500 \mathrm{~m}$ critical receptor location are not expected to greatly exceed the $\chi / Q$ values at $500 \mathrm{~m}$ due to the large area source. Thus, for example the dose to a receptor at $100 \mathrm{~m}$ will be limited by the frequency of wind in that sector which is less than $11 \%$ of the time for any sector. This confirms the critical off-site 
location as being in the canyon, assuming the validity of the canyon flow entrainment of mesa top releases.

\section{Population Center Location}

A similar analysis can be applied to the nearest population center assumed to be $2 \mathrm{~km}$ from Area $\mathrm{G}$ in the (E-ESE) direction (present boundary of White Rock). In this case, dispersion from the $W$ sector contributes directly for all hours. During the night time conditions, wind from the WNW through the E sectors is assumed to drain into Pajarito Canyon which is then assumed to flow down canyon and to the receptor location at White Rock.

The same analysis as above for the Canada del Buey receptor location is applied to the WR location, summing Gaussian dispersion at $2 \mathrm{~km}$ over $\theta=$ WNW to E, correcting for the nighttime wind frequency occurance and for the canyon flow speed, and now adding the full time dispersion contribution from the $\mathrm{W}$ sector. The nighttime occurance for the sector range, $\theta=W N W$ to $E$, is evaluated from the wind roses to be 0.57 . Summing and correcting this range of Gaussian dispersion values from Table I gives $\chi / Q=1.7 \times 10^{-5}$ and $5.4 \times 10^{-6} \mathrm{~s} / \mathrm{m} 3$ respectively, at distances of $1500 \mathrm{~m}$ and $3000 \mathrm{~m}$. Interpolating to the population center location at $2000 \mathrm{~m}$ gives $\chi / Q=1.3 \times 10^{-5}$ $s / m 3$. This is the value used in the analysis of the population center dose assessment.

This dispersion value which accounts for complex terrain can be compared to the maximum dispersion along a single sector (to the $\mathrm{SE}$ ) which is $x / Q=3 . x 10^{-6} \mathrm{~s} / \mathrm{m} 3$ evaluated at $2000 \mathrm{~m}$. The complex terrain increases the Gaussian dispersion at this location by $1.3 \times 10^{-5} / 3 . \times 10^{-6}=4.3$. Since 1.7 is the correction factor due to wind speed reduction in the canyons, canyon channeling contributes an increase at this location of $4.3 / 1.7=2.5$. This is nearly identical to the case for the critical receptor in Canada del Buey and shows the canyon channeling can increase the Gaussian plume predictions by about 2.5 for the daytime maximum (upstream in Canada del Buey) or for the nighttime maximum downstream in Pajarito Canyon.

The canyon wind speed reduction may not be applicable at the White

Rock receptor location because the canyons have essentially dissipated to nearly level terrain there. If we neglect the canyon wind speed reduction 
correction then the White Rock location $\chi / Q$ value would be closer to $1.7 \times 1.3$ $x 10^{-5} \mathrm{~s} / \mathrm{m} 3=2.2 \times 10^{-5} \mathrm{~s} / \mathrm{m} 3$.

The ratio in $\chi / Q$ values between the two sites is about $5.5 / 1.3=4.2$. This appears to be small compared to a ratio of about 10 expected between two points at $500 \mathrm{~m}$ and $2000 \mathrm{~m}$ under the same meteorologic conditions. This is attributed to the difference in day and night dispersion, with less dispersion at night at the White Rock site, increasing the concentration there, and thus reducing the ratio of concentrations at the Canada del Buey to White Rock locations.

\section{Uncertainties}

The data base for both the mesa top wind conditions and for the canyon conditions are relatively good and the uncertainties in the annual averages are probably negligibly small. The dominant uncertainty enters from the model itself, both in the Gaussian plume dispersion and in the formulation of the complex terrain correction given by the sector summation equation above. Predicting flow and pollutant dispersion in complex terrain is part art and part science. Major sources of uncertainty identified with this model follow.

1. The choice of area input as the model source is somewhat arbitrary compared to various conceivable area sources from Area $G$ in the long term future transport and waste exposure scenarios. The sensitivity to this parameter is not known but could be explored by several CAP-88 runs.

2. The critical receptor location is at $500 \mathrm{~m}$. The sensitivity here is related to that in item 1 and these could be evaluated together.

3. The canyon-entrained flow fraction, $f_{\theta}$, may be less than unity as was assumed here to be consevative. This could be evaluated from tracer field studies or from $2 \mathrm{D}$ or $3 \mathrm{D}$ simulations. This may overestimate the off-site concentrations by a factor of 2 to 5 (assuming at least $20 \%$ of the release is entrained in the canyon flow).

4. The wind sectors to be included in the flow contribution to the critical canyon receptor may be different or may be fractional values of some sectors. Similarly to \#3 this could be evaluated by simulations.

5. The Gaussian plume parameter values may be different at Los Alamos than the standard Pasquill-Gifford values used in CAP-88. Some analysis in 
this direction [Bowen,90] indicates that the dispersion is larger at Los Alamos than the default Pasquill-Gifford values, the result of increased turbulence from the enhanced surface roughness in the mesa-riddled terrain.

6. The complex terrain correction may include other factors, or may need to include the factors in better ways. This is subect to future research.

7. Reduction of the canyon dispersion by the wind speed factor of 1.7 at the White Rock location may be inappropriate since the canyons essentially dissipate at this location. This becomes a 70\% uncertainty term.

8. The simplification used to evaluate $c d f_{d a y} / c d f_{a n}$ ignores the different distributions of stability class which exist in the daytime compared to all hours. An improvement in this area would be to generate the Gaussian plume dispersion parameters separately for the daytime and for the night time observations. This would allow a more accurate summation of the canyon channeling effects. The separation of day or night hour observations could be defined to coincide with the time observed for the reversal of the canyon flow direction to improve the model.

Overall the uncertainties suggest in a qualitative manner that the dispersion estimate is good to within a factor of 2-3. If a lognormal distribution is assumed to characterize the estimates of the offsite dispersion, then the estimates given can be considered as the geometric values with geometric standard deviation of 2-3.

\section{Discussion}

More detailed assessments utilizing 2D modeling [Celada and Vold] and 3D modeling [Costigan and Bossert, 96] are in process. The 2D studies are expected to shed light on the canyon partition function, $f_{\theta}$. Fig.7 [from Bossert, 1995] shows a 3D simulation for a potential pollutant dispersing during daytime from a Los Alamos mesa top site. It is seen that the pollutant blows first to the NE in the dominant mesatop flow and is then channeled up canyon before being dispersed from the canyon and carried on to the north in the mesa top flow again. The meteorological field data from around Area $G$ suggests that the strong canyon driven flow will yield similar results for an Area $G$ release. This simulation result is consistent with the critical receptor location identified for the Area G Performance Assessment. 
Simulations have recently been performed for the Area G site [Costigan and Bossert,96], showing similar results to the example in Fig.7 in some instances, while showing less effect of the channeling by the canyons in other instances. These simulations suggest that the assumption made in this study of canyon channeling, which decreases the atmospheric dilution in the critical canyon locations, will be conservative compared to atmospheric dispersion in the real world.

\section{Acknowledgment}

This work was supported by the U.S. Department of Energy, Waste Management Programs and was conducted as part of the Performance Assessment for the disposal facilities at Area G.

\section{References}

Archuleta, J., Barr, S., Clements, W.E., Gedayloo, T., Wilson, S.K., "Some Atmospheric Tracer Experiments in Complex Terrain at LASL", Los Alamos National Laboratory Report LA-7198-MS, Vol.I, Los Alamos, NM, March, 1978.

Bossert, J., personnal communication, EES-5, Los Alamos National Laboratory, Los Alamos, NM, 1995.

Bowen, B.M., Los Alamos Climatology, Los Alamos National Laboratory Report LA-11735-MS, Los Alamos, NM, 1990.

CAP-88, available as CCC-542 from Radiation Shielding and Information Center, Oak Ridge National Laboratory, Oak Ridge, TN 37831.

Celada, R. and Vold, E., The Simple Atmospheric Model (SAM): Development and Preliminary Environmental Transport Applications at a Waste Disposal Site, in preparation as a Los Alamos National Laboratory Report, Los Alamos, NM, 1995. 
Costigan, K.R., and Bossert, J.E., "Three-dimensional modeling study of atmospheric circulations and dispersion at TA-54", Los Alamos National Laboratory Report LAUR-96-4793, Los Alamos, NM, 1996.

EPA - 40CFR61 - Code of Federal Regulations, Volume 40 - Protection of the Environment, Part 61 - National Emmission Standards for Hazardous Pollutants, subpart 61.93.

ESR-94 - Environmental Surveillance at Los Alamos during 1994, Los Alamos National Laboratory Report LA-13047-ENV, Los Alamos, NM, 1996.

Kowalewsky, K., Eklund, B., Vold, E., Air Quality Impacts Analysis for Area G, final report $4 / 4$ from RADIAN to LANL under DOE subcontract 6345L0014-31, with CST-14, Los Alamos National Laboratory, NM, 1995.

Slade, D.H., ed., Meteorology and Atomic Energy 1968, U.S. Atomic Energy Commision, report TID-24190, NTIS, U.S.Dept. of Commerce, Springfield, VA, 22161.

Vold, E.L., Chan, M., Sanders, L., Preliminary Results from the Los Alamos TA54 Complex Terrain Atmospheric Transport Study, Los Alamos National Laboratory Report LAUR-95-2222, Los Alamos, NM, 1995, and in preprint volume of the AMS Ninth Joint Conf. on the Applic. of Air Pollution Meteorology, paper 8A.9, p.464, Atlanta, Jan.28, 1996, American Meteorological Society, Boston, MA. 
Table I

GROUND-LEVEL $\chi / Q$ VALUES WITH NO DEPOSITION $\chi / Q$ (SEC/CUBIC METER) TOWARD INDICATED DIRECTION (for TA54/WR 1992 meteorologic data)

\begin{tabular}{|c|c|c|c|c|c|c|}
\hline \multirow[b]{2}{*}{ Dir } & \multicolumn{6}{|c|}{ Distance (kilometers) } \\
\hline & 0.5 & 1.5 & 3. & 6. & 11.5 & 25. \\
\hline
\end{tabular}

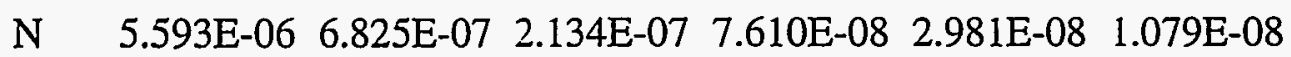
NNW 3.338E-06 3.461E-07 1.058E-07 3.661E-08 $1.436 \mathrm{E}-08 \quad 5.310 \mathrm{E}-09$ NW 2.589E-06 3.229E-07 9.821E-08 $3.422 \mathrm{E}-08 \quad 1.389 \mathrm{E}-08 \quad 5.456 \mathrm{E}-09$ WNW 2.965E-06 3.292E-07 9.785E-08 3.285E-08 1.324E-08 5.187E-09 W $\quad 3.766 \mathrm{E}-06 \quad 4.885 \mathrm{E}-07 \quad 1.464 \mathrm{E}-07 \quad 4.989 \mathrm{E}-08 \quad 2.027 \mathrm{E}-08 \quad 8.021 \mathrm{E}-09$ WSW 5.946E-06 6.161E-07 1.867E-07 6.393E-08 2.525E-08 9.492E-09 SW $\quad 8.900 \mathrm{E}-06 \quad 1.276 \mathrm{E}-06 \quad 3.997 \mathrm{E}-07 \quad 1.445 \mathrm{E}-07 \quad 5.781 \mathrm{E}-08 \quad 2.205 \mathrm{E}-08$ SSW 1.220E-05 1.640E-06 5.226E-07 1.946E-07 7.933E-08 $3.109 \mathrm{E}-08$ S $\quad 1.473 \mathrm{E}-05 \quad 2.019 \mathrm{E}-06 \quad 6.474 \mathrm{E}-07 \quad 2.440 \mathrm{E}-07 \quad 1.009 \mathrm{E}-07 \quad 4.070 \mathrm{E}-08$ SSE 1.995E-05 2.316E-06 7.442E-07 2.815E-07 1.170E-07 4.784E-08 SE $\quad 2.381 \mathrm{E}-05 \quad 3.887 \mathrm{E}-06 \quad 1.251 \mathrm{E}-06 \quad 4.762 \mathrm{E}-07 \quad 1.989 \mathrm{E}-07 \quad 8.204 \mathrm{E}-08$ ESE 2.372E-05 3.237E-06 1.040E-06 3.951E-07 1.647E-07 6.766E-08 E $\quad 1.786 \mathrm{E}-05 \quad 2.475 \mathrm{E}-06 \quad 7.943 \mathrm{E}-07 \quad 3.017 \mathrm{E}-07 \quad 1.256 \mathrm{E}-07 \quad 5.127 \mathrm{E}-08$ ENE 1.354E-05 1.499E-06 4.799E-07 1.813E-07 7.501E-08 3.027E-08 NE $\quad 1.088 \mathrm{E}-05 \quad 1.622 \mathrm{E}-06 \quad 5.178 \mathrm{E}-07 \quad 1.931 \mathrm{E}-07 \quad 7.883 \mathrm{E}-08 \quad 3.099 \mathrm{E}-08$ NNE $\quad 8.802 \mathrm{E}-06 \quad 1.257 \mathrm{E}-06 \quad 3.969 \mathrm{E}-07 \quad 1.438 \mathrm{E}-07 \quad 5.676 \mathrm{E}-08 \quad 2.071 \mathrm{E}-08$ 


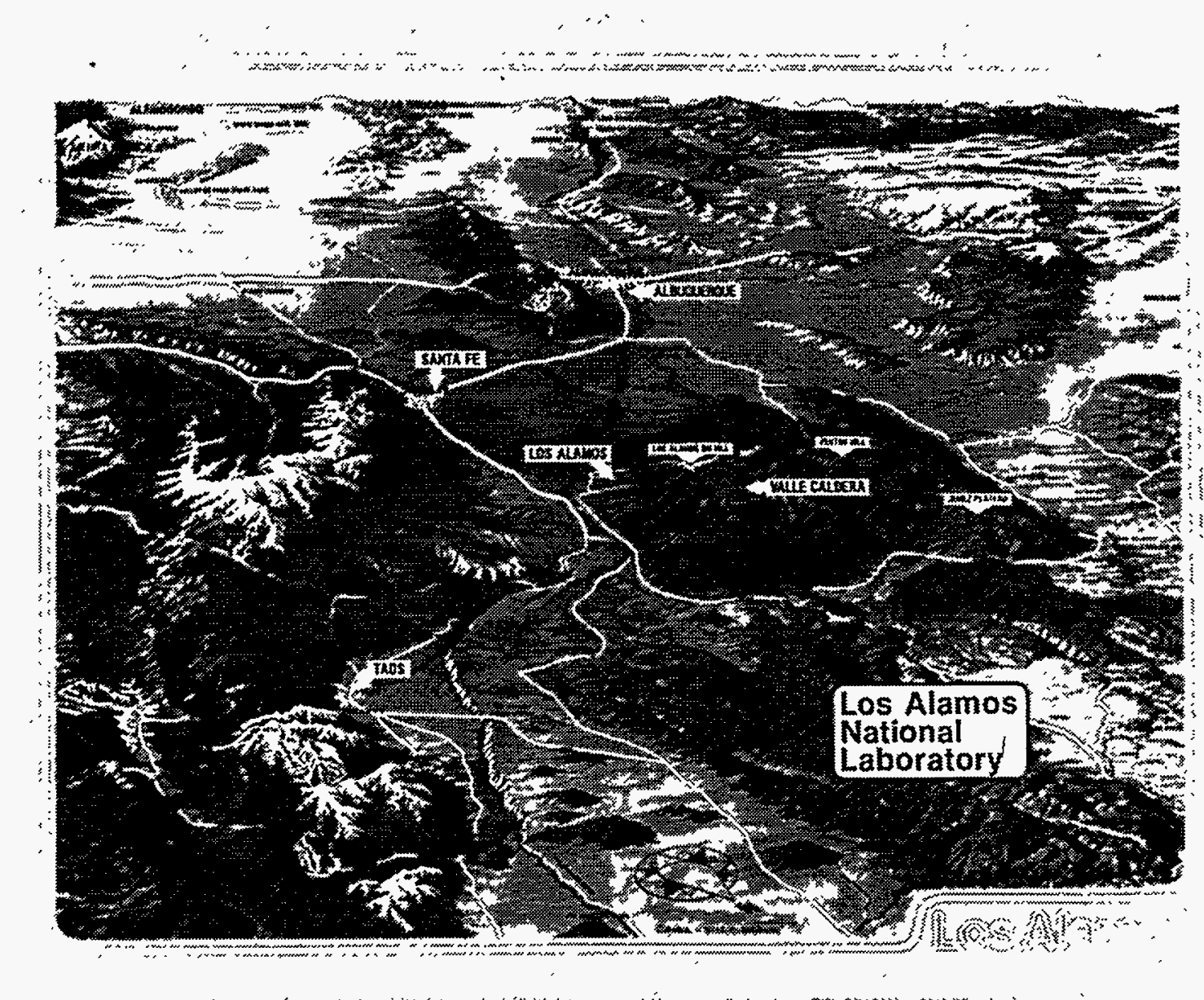

Fig.1 Northern New Mexico from the NNE. The Rio Grande valley lies between the Sangre de Cristos Range to the east (left in the figure) and the Jemez and Valle Caldera to the west of Los Alamos. This channels the wind to be predominantly from the SSW. 


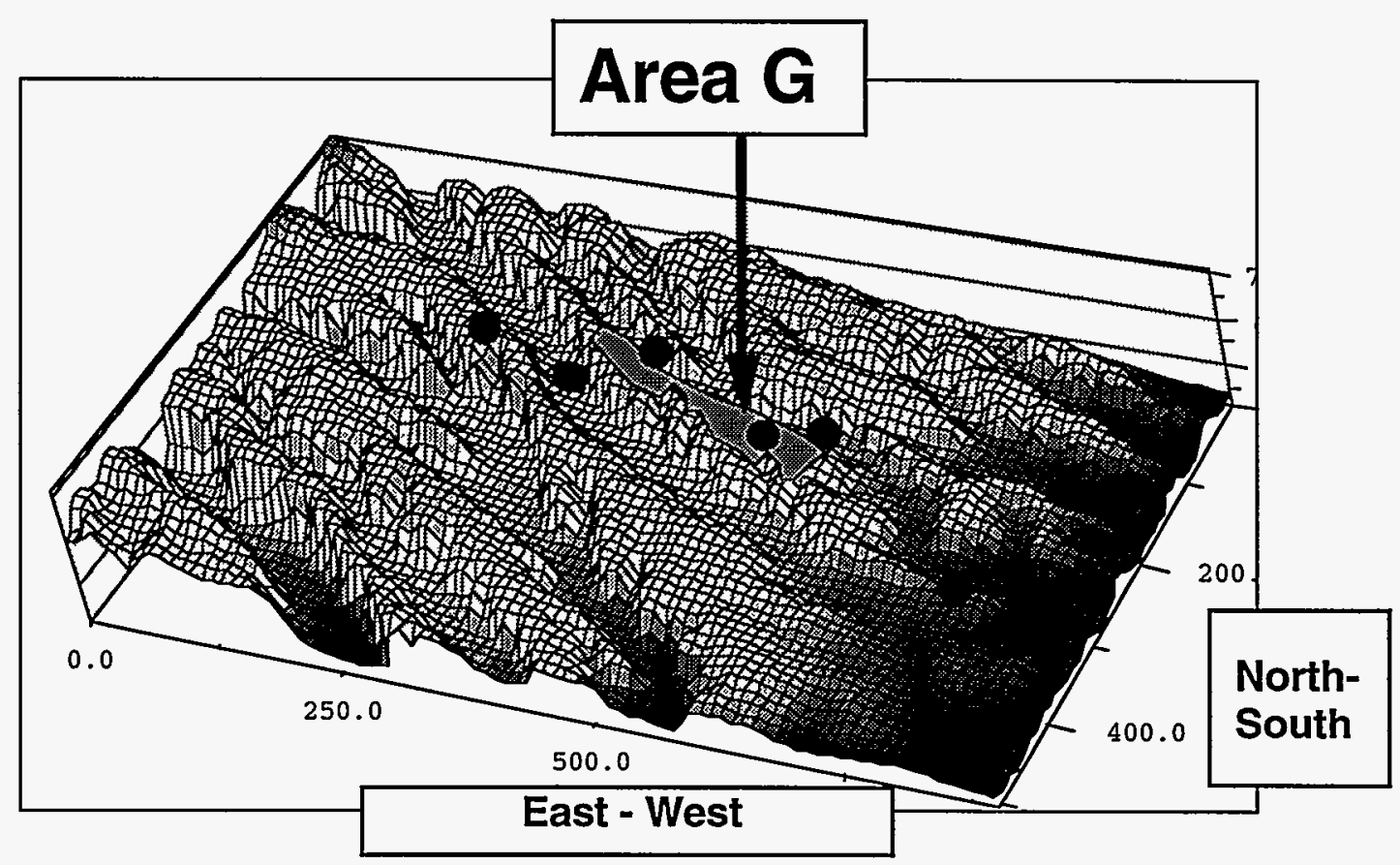

- Meteorological tower locations (6)

Fig.2 Area $G$ complex terrain and remote meteorological station locations. Axis scale: units $=20 \mathrm{ft}$. The whole area shown is about $4 \mathrm{~km}(\mathrm{E}-\mathrm{W})$ by $2 \mathrm{~km}$ (N-S). 


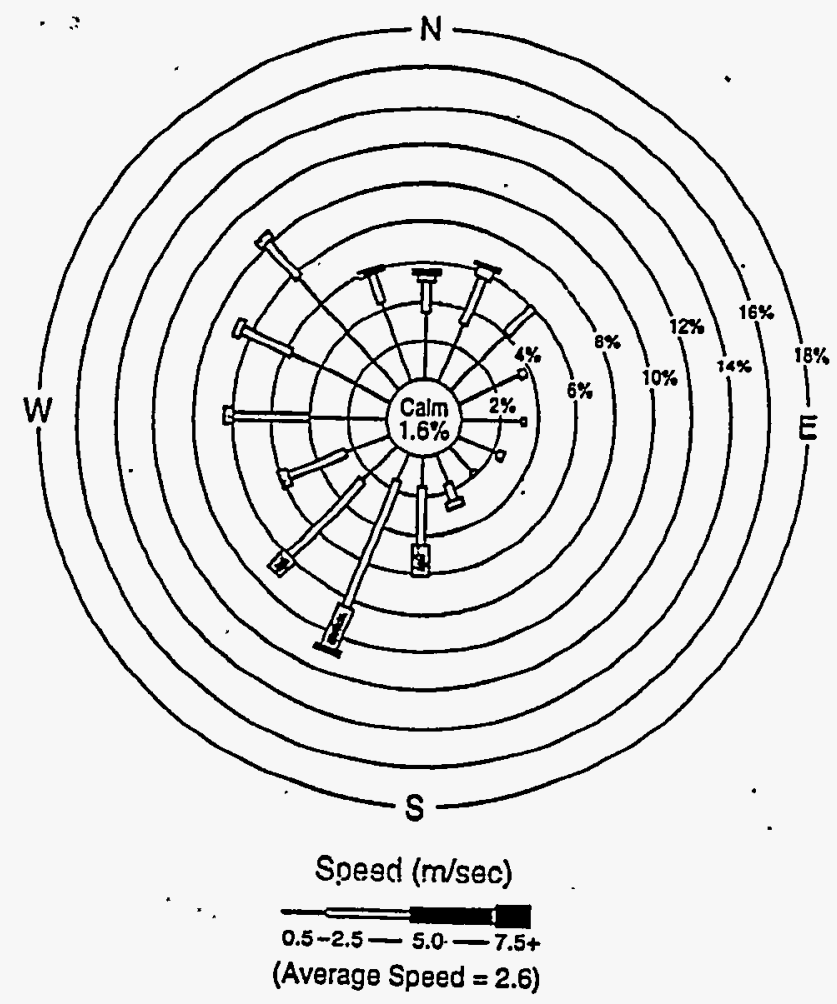

Fig.3 Annual average windrose - Area G 1992.
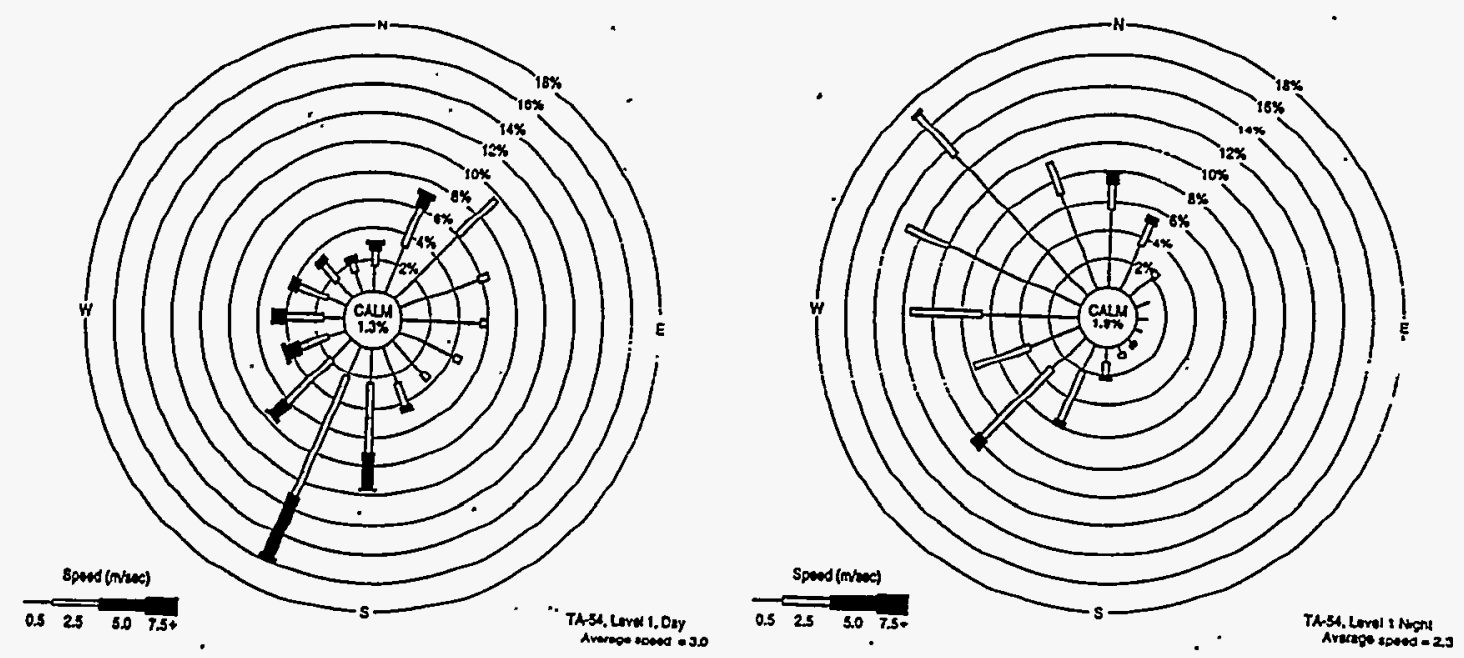

Fig.4 Day time wind rose for Area G 1992 Fig.5 Night time wind rose. 

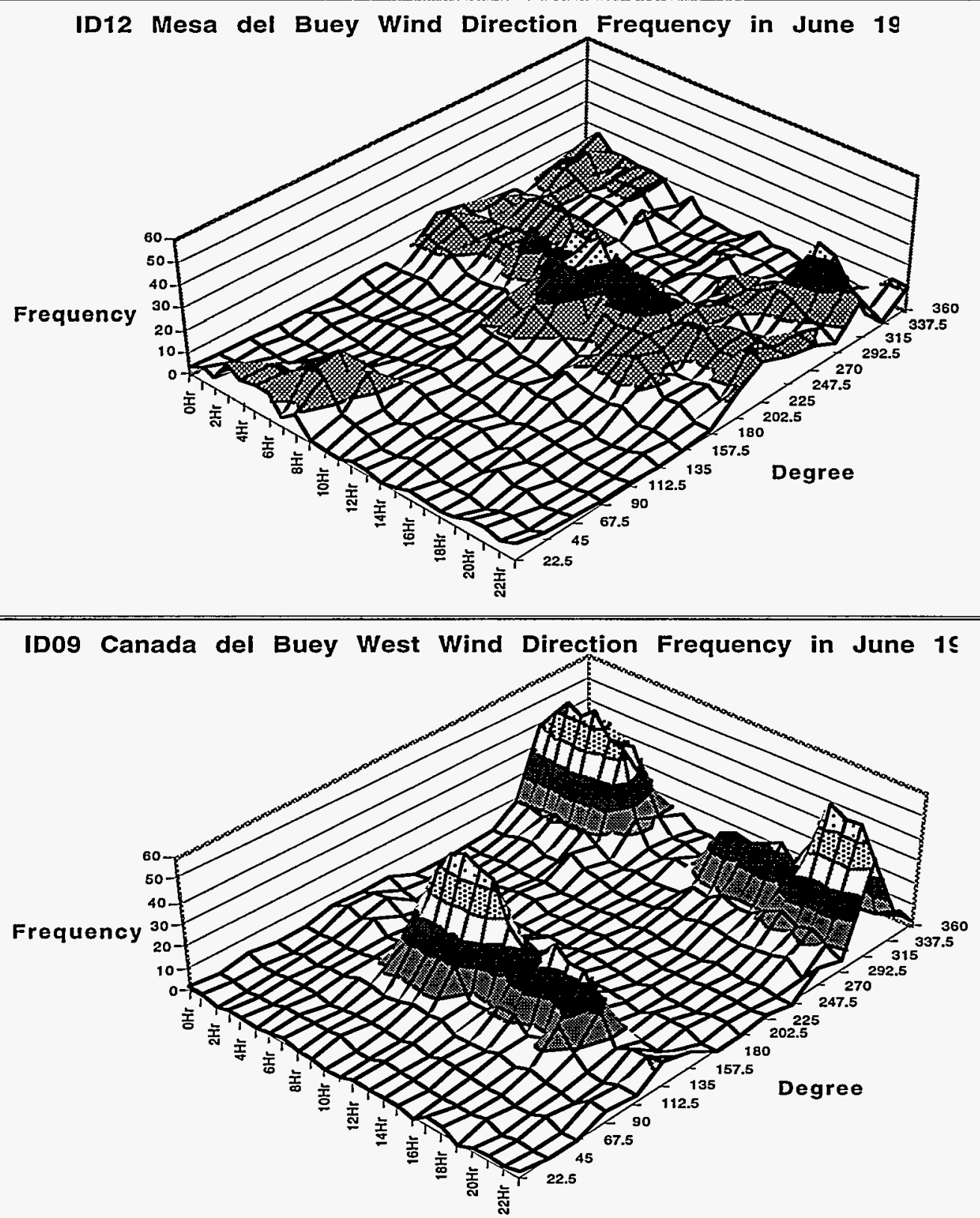

Fig.6a (top) shows the frequency distribution for wind direction and time of day in June 1995 at the mesa top location at Area G (shown in Fig.2).

Fig.6b (bottom) shows the frequency distribution for wind direction and time of day in June 1995 at a canyon location (Canada del Buey as shown in Fig.2). 

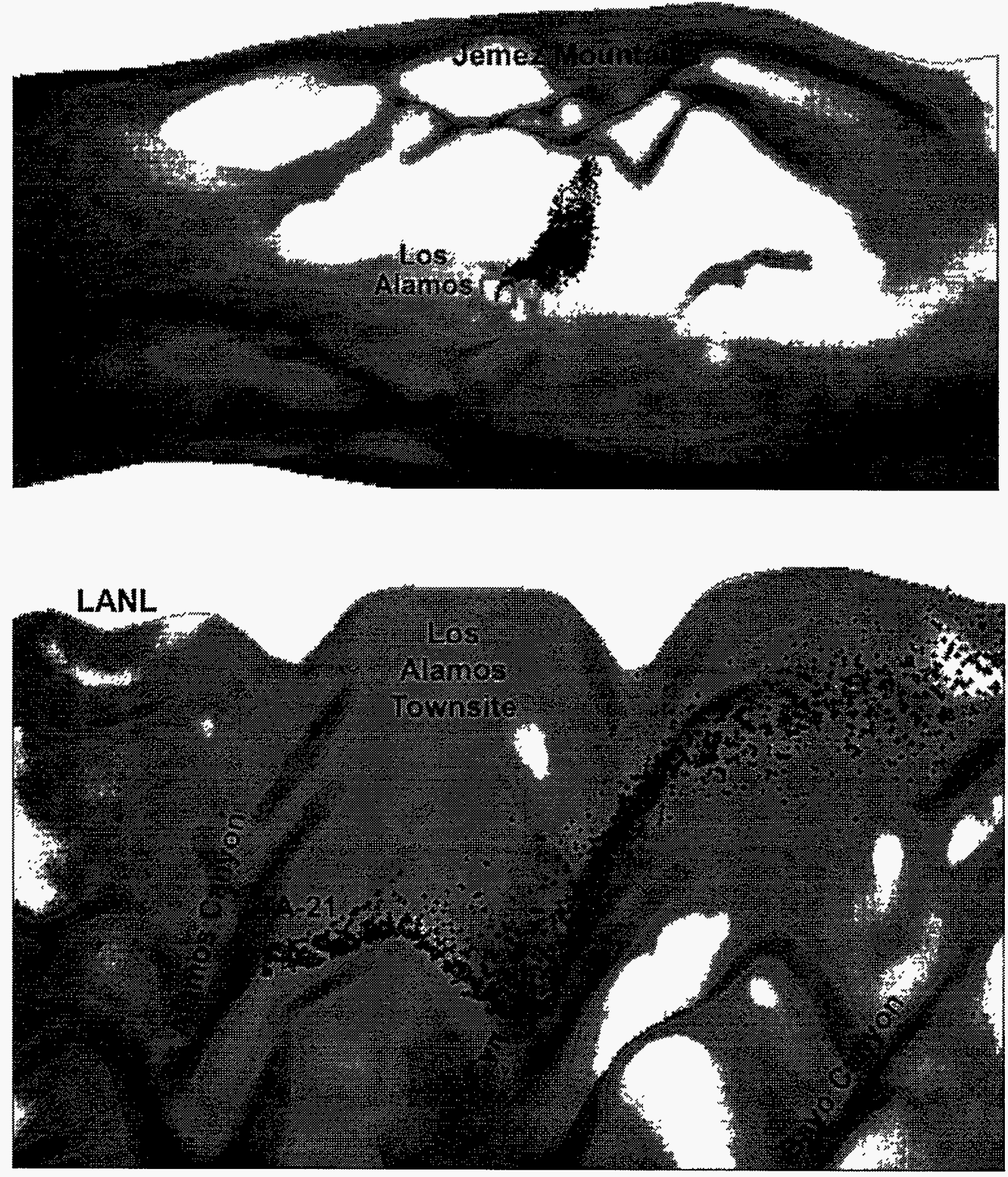

Fig. 7 Atmospheric simulation in Los Alamos complex terrain shown on two different scales (ref: J. Bossert, personal communication). A normalized source is located at TA-21. Similar results are expected from Area G, TA-54. 